\title{
Tympanostomy tube insertion practice in under-18-year-olds in the South African private healthcare sector insured by Discovery Health
}

\author{
E Samson, ${ }^{1}$ MB BCh, MMed (Otol), FCORL (SA); G Quail, ${ }^{1}$ MB BCh, MMed (Otol), FCORL (SA); \\ S Peer, ${ }^{2}$ MB BCh, MMed (Otol), FCORL; J J Fagan, ${ }^{1}$ MB ChB, FCS (SA), MMed (Otol) \\ ${ }^{1}$ Division of Otolaryngology, Faculty of Health Sciences, University of Cape Town, South Africa \\ ${ }^{2}$ Division of Otolaryngology, Red Cross War Memorial Children's Hospital and Faculty of Health Sciences, University of Cape Town, South Africa
}

Corresponding author: E Samson (evesamson@gmail.com)

\begin{abstract}
Background. The reported rates of tympanostomy tube insertion (TTI) in children vary significantly internationally. Lack of adherence to evidence-based clinical guidelines may contribute to these differences.

Objectives. To study the rates of TTI in South Africa (SA) in children $\leq 18$ years old in the private healthcare sector, both nationally and regionally, to compare these with international TTI rates, and to determine the use of preoperative audiometry and tympanometry.

Methods. A retrospective analysis was done of data obtained from the Discovery Health database. Rates of TTI were analysed nationally and regionally and in different age groups, as was the use of tympanometry and audiograms.

Results. The SA TTI rates were much higher than published international rates except for the 0 - 1 -year age group in Canada and Denmark and the 0 - 15-year age group in Denmark. There was a statistically significant regional variation in TTI rates as well as in the use of preoperative audiometry and tympanometry.

Conclusions. SA private sector TTI rates are high by international standards. Significant regional variations may indicate over- or underservicing in certain regions. Further investigation of causes for the high TTI rate and regional variations is recommended. Education of healthcare professionals on recognised indications for TTI may improve patient selection.
\end{abstract}

S Afr Med J 2019;109(6):421-425. DOI:10.7196/SAMJ.2019.v109i6.13189

Tympanostomy tube insertion (TTI) in children is employed principally for otitis media with effusion (OME) lasting $\geq 3$ months with significant hearing loss (hearing loss of $\geq 25 \mathrm{~dB}$ in the betterhearing ear), to restore middle ear ventilation and shorten the duration of the effusion, but principally to improve hearing. ${ }^{[1]}$ However, TTI is not without risk of complications and can cause otorrhoea, granulations, scarring, perforation, atrophy and retraction of the tympanic membrane. ${ }^{[2]}$ Early extrusion or medial displacement of the tympanostomy tube can occur. ${ }^{[2]}$ Complications of untreated acute otitis media and prolonged middle ear effusion include the potential risk of learning and language delay, recurrent courses of antibiotics with the risk of antibiotic resistance, and tympanic membrane changes. ${ }^{[3]}$

The American Academy of Otolaryngology-Head and Neck Surgery (AAO-HNS), ${ }^{[4]}$ the American Academy of Pediatrics $(\mathrm{AAoP})^{[5,6]}$ and the National Institute of Clinical Excellence (NICE) ${ }^{[7]}$ publish management guidelines for TTI. The AAoP recommends TTI for patients with persistent OME after a period of watchful waiting for 3 months, for patients with OME associated with speech, language or learning delay, ${ }^{[6]}$ or for recurrent acute otitis media (rAOM), defined as three episodes in 6 months or four episodes in 1 year with one episode in the preceding 6 months. ${ }^{[5]}$ The NICE guidelines recommend TTI for OME with a reduced hearing threshold of $\geq 25 \mathrm{~dB}$ in the better-hearing ear that has persisted for $\geq 3$ months. ${ }^{[7]}$ Both the AAoP and NICE guidelines require ageappropriate preoperative hearing assessment to be performed.

Reported rates of TTI differ widely between countries, with significant regional variations. ${ }^{[8,9]}$ The TTI rate in South Africa (SA) has not been reported previously. The present study focuses only on TTI rates in privately insured SA patients as, in contrast to the public health sector, such patients have good access to TTI and are therefore more comparable to reports emanating from developed countries. Because Discovery Health (DH) has a 30\% market share of the SA medical insurance market, its members are a good proxy for private TTI practice in SA. ${ }^{[10]}$

\section{Methods}

\section{Study design and population}

A retrospective review was done of all TTI cases in the national DH database for the 0 - 18-year age group over a period of 2 years (1 January 2012 - 31 December 2013). No patients were excluded. For the purpose of the study, a TTI was defined as a hospital admission for TTI. Admission for myringotomy and/or uni- or bilateral TTI was recorded as a single TTI. Insurance claims for preoperative tympanometry and audiometry were also recorded for the TTI patients.

Ethical approval for the study was obtained from the University of Cape Town Human Ethics Committee (ref. no. 015/2015).

\section{Data analysis}

Variations in TTI rates between regions were reported according to the Dartmouth Atlas of Regions. ${ }^{[1]}$ Patients were clustered into age groups to compare TTI rates with reported international rates. The proportion of TTI patients for whom insurance claims had been lodged for preoperative tympanometry and audiometry was determined. A $\chi^{2}$ test for trend was used to assess the association 
between rates of preoperative tympanometry and audiometry. A $p$-value $<0.05$ was used as the cut-off for statistical significance.

\section{Results}

Among 74126 patients aged $\leq 18$ years who were insured by $\mathrm{DH}$, there were 22493 admissions for TTIs, with similar numbers and TTI rates in 2012 and 2013 (Table 1).

SA TTI rates compared with international rates according to age group are presented in Table 2. The SA TTI rates were much higher than published international rates, except for the 0 - 1-year age group in Canada and Denmark and the 0 - 15 -year age group in Denmark.

\section{Age distribution of TTI}

Fig. 1 and Table 3 illustrate the age distribution of TTI in SA patients. The majority were children aged $0-6$ years, with a peak age of 0 - 2 years.

\section{Regional variations}

There were wide regional variations of TTI rates in SA, with rates ranging between 69 and 246 per 10000 (Fig. 2); the TTI rates varied by a factor of 3.6 between the lowest and the highest region. The

\begin{tabular}{|c|c|c|}
\hline Year & Total TTIs, $n$ & TTIs/10 000 \\
\hline 2012 & 11074 & 149 \\
\hline 2013 & 11419 & 148 \\
\hline Total & 22493 & 149 \\
\hline
\end{tabular}

TTI = tympanostomy tube insertion. regional TTI rate in <1-year-olds ranged between 22 and 176 per 10000 , i.e. by a factor of 8 (Fig. 3).

\section{Regional ratio of DH members to ENT surgeons}

The regional ratio of the number of $\mathrm{DH}$ members to ear, nose and throat (ENT) surgeons varied widely (Fig. 4). However, the

\begin{tabular}{ll} 
Table 3. TTIs in SA according to age \\
\hline Age group (years) & TTIs/10 000 \\
\hline $0-2$ & 380 \\
$3-4$ & 318 \\
$5-6$ & 171 \\
$7-12$ & 44 \\
$13-18$ & 9 \\
SA = South Africa; TTI = tympanostomy tube insertion.
\end{tabular}

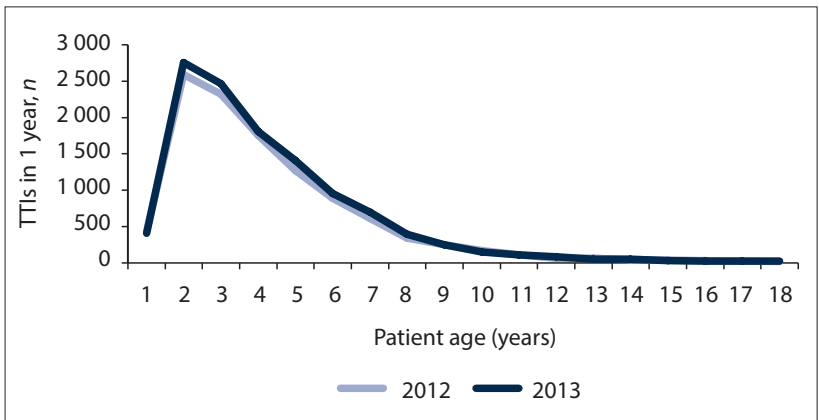

Fig. 1. TTI rates according to age in the study population. $($ TTI $=$ tympanostomy tube insertion.)

\begin{tabular}{|c|c|c|c|}
\hline Age group (years) & Country & TTIs/10 000 & SA TTI rate relative to other countries \\
\hline $0-18$ & SA & 149 & \\
\hline \multirow[t]{3}{*}{$0-16$} & SA & 334 & \\
\hline & Finland $^{[8]}$ & 51 & 6.55 \\
\hline & Norway $^{[8]}$ & 43 & 7.77 \\
\hline \multirow[t]{7}{*}{$0-15$} & SA & 350 & \\
\hline & Denmark $^{[27]}$ & 400 & 0.88 \\
\hline & Canada ${ }^{[28]}$ & 111 & 3.15 \\
\hline & $\mathrm{USA}^{[29]}$ & 89 & 3.93 \\
\hline & Australia ${ }^{[18]}$ & 56 & 6.25 \\
\hline & Scotland ${ }^{[30]}$ & 47 & 7.45 \\
\hline & $\mathrm{UK}^{[31]}$ & 21 & 16.67 \\
\hline \multirow[t]{2}{*}{$0-14$} & SA & 367 & \\
\hline & Canada $^{[17]}$ & 84 & 4.37 \\
\hline \multirow[t]{3}{*}{$0-12$} & SA & 197 & \\
\hline & New Zealand ${ }^{[20]}$ & 69 & 2.86 \\
\hline & $\mathrm{UK}^{[20]}$ & 40 & 4.93 \\
\hline \multirow[t]{3}{*}{$0-7$} & SA & 578 & \\
\hline & Finland ${ }^{[32]}$ & 147 & 3.93 \\
\hline & Norway $^{[32]}$ & 123 & 4.70 \\
\hline \multirow[t]{2}{*}{$0-4$} & SA & 356 & \\
\hline & Australia $^{[18]}$ & 149 & 2.39 \\
\hline \multirow[t]{3}{*}{$0-1$} & SA & 89 & \\
\hline & Denmark $^{[27]}$ & 1990 & 0.04 \\
\hline & Canada $^{[28]}$ & 128 & 0.70 \\
\hline
\end{tabular}




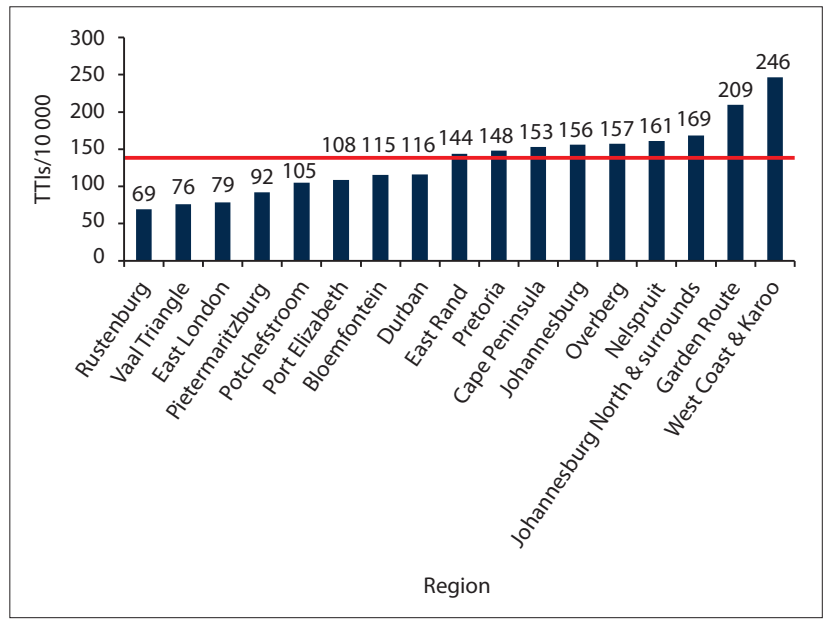

Fig. 2. TTI rates in patients aged $0-18$ years according to region. The red line depicts the national average of 149 TTIs per 10000 insured patients. (TTI = tympanostomy tube insertion.)

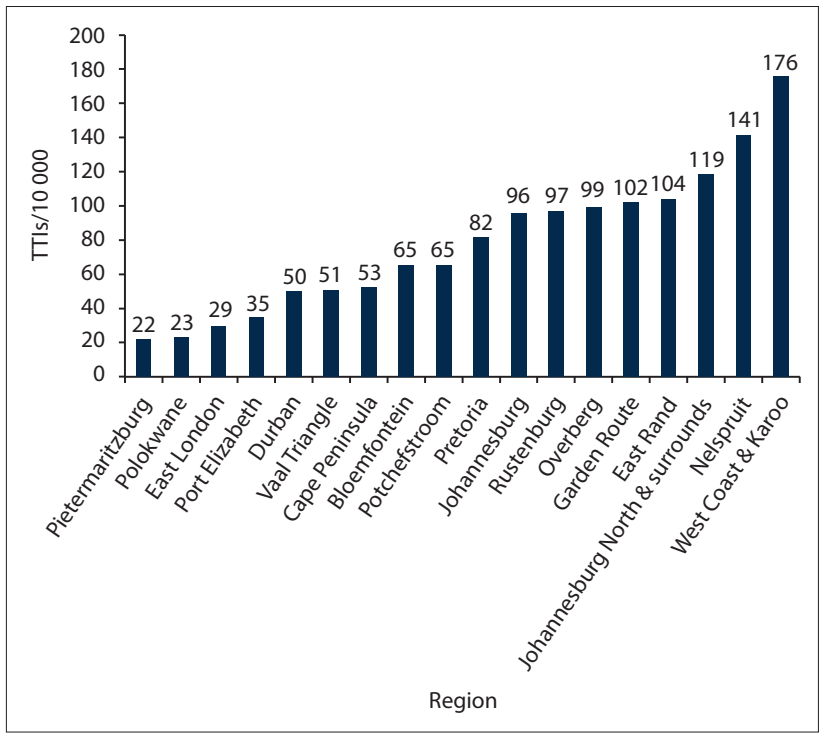

Fig. 3. TTI rates in children aged $<1$ year according to region. (TTI $=$ tympanostomy tube insertion.)

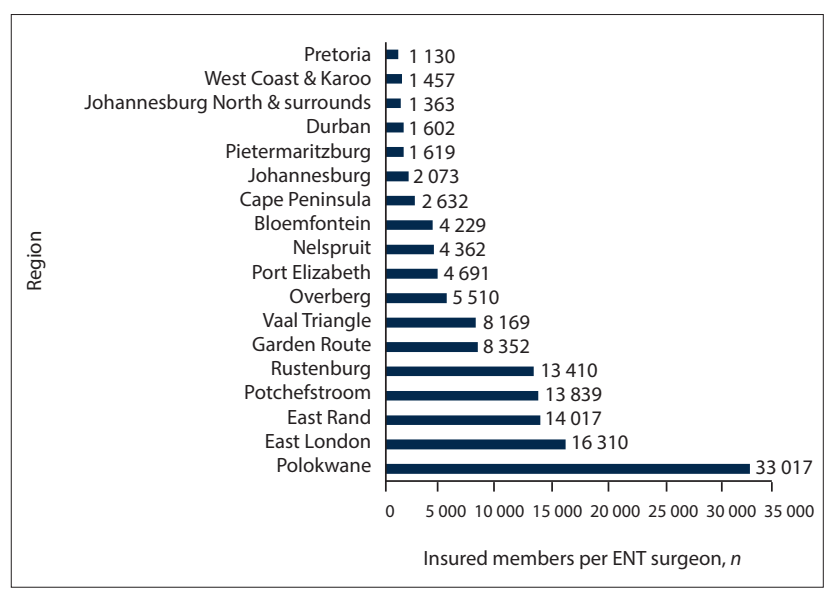

Fig. 4. Number of Discovery Health members per ENT surgeon according to region. (ENT $=$ ear, nose and throat.) correlation between the number of ENT surgeons per 10000 and the TTI rate using Spearman's rank correlation coefficient was not found to be statistically significant $(p=0.1633)$.

\section{Preoperative audiology}

There was significant regional variation in preoperative tympanometry (10 - 56\%) and audiometry (30 - 74\%) rates (Figs 5 and 6). These rates reflect only investigations funded by DH. Out-of-pocket investigations were not available for analysis and were therefore not considered.

\section{Discussion}

OME has a high prevalence in children, but resolves spontaneously in $80 \%$ of patients within 2 months. ${ }^{[12]}$ Ninety percent of children will have had an episode of OME in the first 2 years of life. ${ }^{[12,13]}$ There have been no studies on the prevalence of OME in the private healthcare sector in SA. It was found in a sample of 140 children utilising public healthcare facilities that the prevalence of OME was 16.5\% for children aged between 2 and 16 years. ${ }^{[14]}$ The prevalence of chronic suppurative otitis media in the same population was found to be $6.6 \%$, which is classified by the World Health Organization as high. Because it is so commonly performed, TTI has a significant impact on healthcare costs; USD1.8 billion is spent annually in the USA on

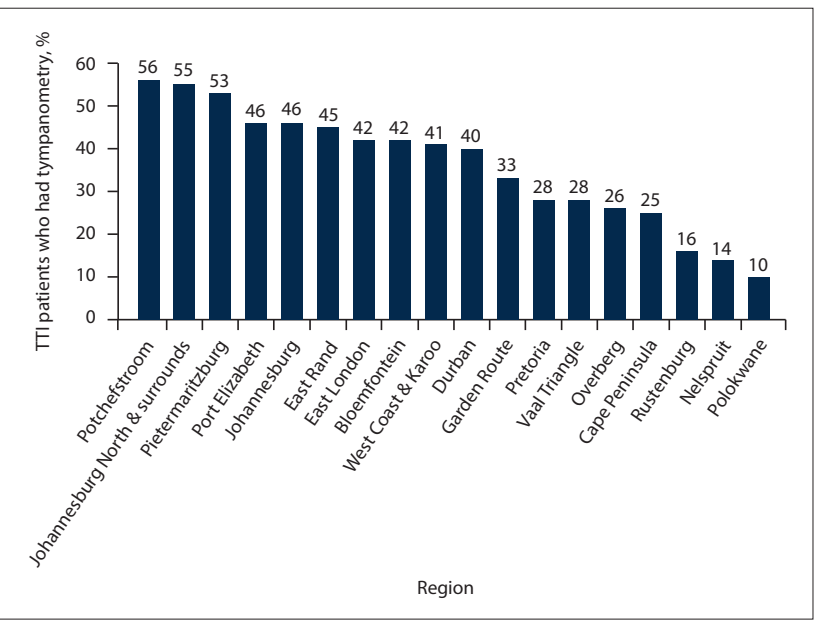

Fig. 5. Proportion of TTI patients who had tympanometry according to region. (TTI = tympanostomy tube insertion.)

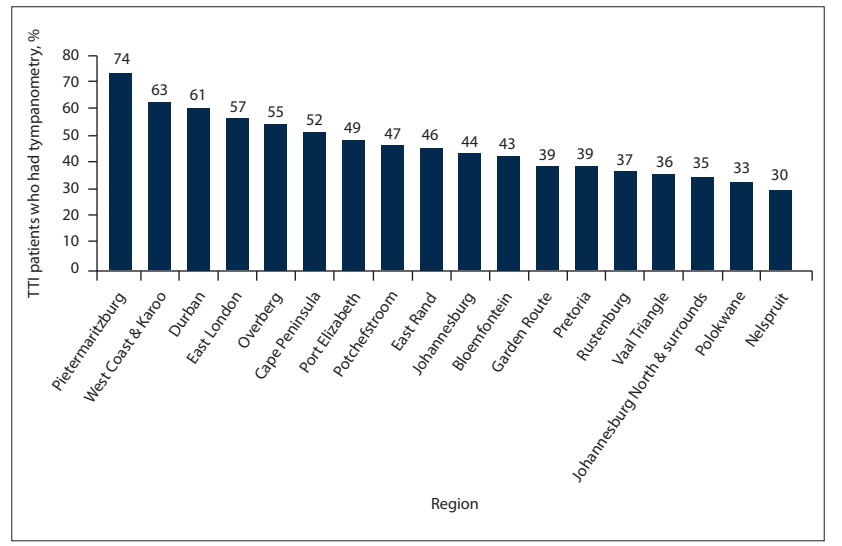

Fig. 6. Proportion of TTI patients who had audiometry according to region. (TTI = tympanostomy tube insertion.) 
the procedure. ${ }^{[15]}$ Best clinical practice aims to identify OME that will resolve spontaneously with watchful waiting without long-term sequelae, and patients who will benefit from the short-term hearing gain and reduction of otitis media episodes offered by TTI. The risks and expense of surgery and general anaesthesia must be weighed against the potential complications of untreated OME, antibiotic use and multiple visits to doctors. International working groups such as NICE, AAoP and AAO-HNS all have established guidelines aimed at reducing inappropriate TTI. ${ }^{[16]}$ Despite access to these, rates of TTI vary between countries in the developed world. ${ }^{[17,18]}$ Keyhani et al. ${ }^{[19]}$ reported that clinicians in a New York-based study did not follow guidelines when recommending TTI, with only $30 \%$ of procedures in accordance with recommended guidelines.

TTI rates in DH patients are a good representation of the TTI rates in the SA private healthcare sector, given the substantial market share of $\mathrm{DH}$. Paediatric TTI rates in the $\mathrm{DH}$ population are the highest in the world other than in Denmark, and in Canada in the $<1$-year-old group of patients. The SA TTI rate in the $<15$-year age group is 16.7 times higher than that in the UK.

Why should the TTI rate be so high in SA, and why should there be significant regional variations in TTI rates? The likely reason is that internationally recognised guidelines for TTI are not being adhered to or uniformly applied. Regional variations were also reported in New Zealand and in Norway. ${ }^{[20,21]}$ The authors of the Norwegian study proposed that regional variation was due to individual interpretation of the Norwegian Medical Association guidelines, the guidelines not being prescriptive, and possible non-medical factors. ${ }^{[15,21]}$ Regional variations reported in Canada and Australia were proposed to be due to the influence of family physicians. ${ }^{[17,18]}$ In a New York study, ${ }^{[22]}$ TTI was performed in cases that did not comply with accepted guidelines, and family disruption and theatre admission for another surgery were factors that influenced TTI. Areas with increased economic resources and/or private healthcare insurance have been found to have higher rates of TTI in Western Australia and in New York. ${ }^{[18,23]}$ It has also been found in the USA that factors other than the prevalence of OME may affect TTI rates, namely race, health insurance and other unknown factors. ${ }^{[23]}$ In our study, an association between regional ENT surgeons per capita and the TTI rate was not significant.

The finding that the majority of TTIs were performed in children aged $<6$ years is in keeping with evidence from the literature that there is a high prevalence of OME and rAOM in this age group. ${ }^{[15]}$

Our audit revealed low overall rates of hearing assessment and tympanometry assessment, with large regional variations, raising the possibility that clinicians in certain regions are not following accepted practice guidelines. Other than for $\mathrm{rAOM}$, preoperative audiometry is required to determine that $\mathrm{OME}$ is accompanied by clinically significant conductive hearing loss prior to TTI. Audiological confirmation that hearing has improved to normal levels following surgery should also be standard practice. Lower audiometry rates in the 0 - 2-year age group could be explained by the indication for surgery being $\mathrm{rAOM}$, but this postulate is unlikely to explain the drop-off in rates of audiometry in older age groups. Regional rate variation in the use of audiometry was also found in Western Australia. ${ }^{[18]}$ Inequitable audiological access was cited as a possible reason for this finding.

The challenge of getting clinicians to apply evidence-based practice guidelines is well known. ${ }^{[24]}$ However, it was shown that medical practice can be changed with passive dissemination of guidelines in the UK, where TTI rates decreased steadily from 1986 to 1992. Following the institution of guidelines, the rate of surgery decreased more rapidly from 1992 to $1997 .{ }^{[25]}$
Campaigns to disseminate information to clinicians and patients may not be enough to change clinical practice and improve adherence to guidelines, as has been shown in Sweden. ${ }^{[26]}$ Peer review groups, open collaboration with pharmacists and accurate practice auditing and feedback have been shown to promote rational prescribing of antibiotics for rAOM in The Netherlands.$^{[9]}$ It has been suggested that these principles could be applied to healthcare systems that operate in a fee-for-service structure to change clinicians' behaviour. ${ }^{[26]}$

\section{Study strengths and limitations}

The strength of the study is that it was a national review with a large sample size, comprising all the TTIs performed on a well-defined population. The audiometry and tympanometry data quoted only include procedures that had been billed to DH; the study did not capture procedures that were paid for privately, and may therefore under-represent the use of these tests. Additionally, data were obtained from administrative sources (the DH database) without correlation with clinical details and knowledge of the indication for tympanostomy tube placement. As no validation of the data could be performed, there is a risk of misclassification, as with any other register-based study.

\section{Conclusions}

The high TTI rate, the possible low use of audiometry and tympanometry, and significant regional variations in TTI rates and use of audiology and tympanometry raise questions about whether internationally recognised best practice for $\mathrm{OME}$ and $\mathrm{rAOM}$ is being consistently adhered to in the private healthcare sector of SA. Increased rates could also be related to an increased burden of disease, and further study on this in the SA private sector population is recommended. Rigorous campaigns are needed to educate all levels of healthcare providers, medical insurance companies and parents about middle ear disease and its management based on internationally recognised practice guidelines.

Declaration. None.

Acknowledgements. We thank Kathryn Manning and Brett Glen for statistical data analysis.

Author contributions. ES and GQ contributed to the conception and design of the study, performed the statistical analysis and interpretation of data, and contributed to drafting the article. SP contributed to the design and drafting of the article. JJF contributed to the conception and design and revision of the article for intellectual content. All authors read and approved the final version of the manuscript.

Funding. None.

Conflicts of interest. None.

1. Browning G, Rovers M, Williamson I, Lous J, Burton M. Grommets (ventilation tubes) for hearing loss associated with otitis media with effusion in children (Review). Cochrane Database Syst Rev 2010, Issue 10. Art. No.: CD001801. https://doi.org/10.1002/14651858.CD001801.pub3

2. Jung TTK, Alper CM, Hellstrom SO, et al. Panel 8: Complications and sequelae. Am Acad Otolaryngol Neck Surg 2012;148(4 Suppl):E122-E143. https://doi.org/10.1177/0194599812467425

Rosenfeld RM, Kay D. Natural history of untreated otitis media. Laryngoscope 2003;113(10):16451657. https://doi.org/10.1097/00005537-200310000-00004

Rosenfeld RM, Shin JJ, Schwartz SR, et al. Clinical Practice Guideline: Otitis media with effusion executive summary (Update). Am Acad Otolaryngol Neck Surg 2016;154(2):201-214. https://doi. org/10.1177/0194599815624407

5. Lieberthal AS, Carroll AE, Chonmaitree $\mathrm{T}$, et al. The diagnosis and management of acute otitis media. Am Acad Pediatr 2013;131(3):e964-e999. https://doi.org/10.1542/peds.2012-3488

6. Rosenfeld RM, Culpepper L, Doyle KJ, et al. Clinical Practice Guideline: Otitis media with effusion. Am Acad Pediatr 2004;113(5):1412-1429. https://doi.org/10.1016/j.otohns.2004.02.002

Am Acad Pediatr 2004;113(5):1412-1429. https://doi.org/10.1016/j.otohns.2004.02.002 National Collaborating Centre for Women's and Children's Health, commissioned by the National
Institute for Health and Clinical Excellence. Surgical Management of Otitis Media with Effusion in Institute for Health and Clinical Excellence. Surgical Management of Otitis Media with Effusion in
Children. London: RCOG Press, 2008. https://www.nice.org.uk/guidance/cg60/documents/cg60surgical-management-of-ome-full-guideline2 (accessed 6 May 2019). 
8. Karevold G, Haapkyla J, Pitka A, Jorunn K. Otitis media surgery: Large variability between Finland and Norway. Int J Pediatr Otorhinolaryngol 2016;71(2007):1035-1039. https://doi.org/10.1016/j. ijporl.2007.03.010

9. Schilder AGM, Lok W, Rovers MM. International perspectives on management of acute otitis media A qualitative review. Int J Pediatr Otorhinolaryngol 2004;68(1):29-36.

10. Streak M. Your Discovery Health Medical Scheme Integrated Annual Report. Johannesburg: Discovery Streak M. Your Discovery Health Medical Scheme Integrated Annual Report. Johannesburg: Discovery
Health, 2012. https://www.discovery.co.za/discovery_coza/web/linked_content/pdfs/health/health Health, 2012. https://www.discovery.co.za/discovery

11. HealthyPeople.gov. Dartmouth Atlas of Health Care. https://www.healthypeople.gov/2020/data-source/ HealthyPeople.gov. Dartmouth Atlas of Health Care. h
dartmouth-atlas-of-health-care (accessed 6 May 2019).

12. Paradise JL, Dollaghan CA, Campbell TF, et al. Otitis media and tympanostomy tube insertion during the first three years of life: Developmental outcomes at the age of four years. Pediatrics 2003;112(2):265-277. https://doi.org/10.1542/peds.112.2.26

13. Casselbrant ML, Kaleida PH, Rockette HE, et al. What is the role of tympanostomy tubes in the treatmen of recurrent acute otitis media? Laryngoscope 2013;123(12):E127. https://doi.org/10.1002/lary.2414

14. Biagio L, Swanepoel DW, Laurent C, Lundberg T. Paediatric otitis media at a primary healthcare clinic in South Africa. S Afr Med J 2014;104(6):431-435. https://doi.org/10.7196/SAMJ.7534

15. Rosenfeld RM, Schwartz SR, Pynnonen MA, et al. Clinical practice guideline: Tympanostomy tubes in children. Otolaryngol Head Neck Surg 2013;149(1 Suppl):S1-S35. https://doi org/10.1177/0194599813487302

16. National Institute for Health and Clinical Excellence. Surgical management of otitis media with effusion in children. NICE Clinical Guideline 60. 2008. http://www.albert.uk.com/fileadmin/user_upload/ Uploaded_files/tmp/david_albert/david_albert_doc/OME.pdf (accessed 6 May 2019).

17. Coyte PC, Croxford R, Asche C V, To T, Feldman W, Friedberg J. Physician and population determinants of rates of middle-ear surgery in Ontario. JAMA 2001;286(17):2128-2135. https://doi.org/10.1001/ jama.286.17.2128

18. Spilsbury K, Latif Kadhim A, Semmens J, Lannigan F. Decreasing rates of middle ear surgery in Western Australian children. Arch Otolaryngol Head Neck Surg 2006;132(11):1216-1220. https://doi. org/10.1001/archotol.132.11.1216

19. Keyhani S, Kleinman LC, Rothschild M, et al. Clinical characteristics of New York City children who received tympanostomy tubes in 2002. Pediatrics 2008;121(1):e24-e33. https://doi.org/10.1542/ peds.2007-0623

20. National Health Committee, New Zealand. NHC Technology Note: Ventilation tubes: An opportunity for better targeting. January 2013. http://www.moh.govt.nz/notebook/nbbooks.nsf/0/32A0092DD3160A38 better targeting. January 2013. http://www.moh.govt.nz/notebook/nbbooks.nsf/0/32A0092DD3160A38 \%2031-01-13.pdf (accessed 6 May 2019).
21. Karevold G, Haapkylä J, Pitkäranta A, Nafstad P, Kvaerner KJ. Paediatric otitis media surgery in Norway. Acta Otolaryngol 2007;127(1):29-33. https://doi.org/10.1080/00016480600606756

22. Keyhani S, Kleinman LC, Rothschild M, Bernstein JM, Anderson R, Chassin M. Overuse of tympanostomy tubes in New York metropolitan area: Evidence from five hospital cohort. BMJ 2008:337:a1607. https://doi.org/10.1136/bmj.a1607

23. Kogan MD, Overpeck MD, Hoffman HJ, Casselbrant ML. Factors associated with tympanostomy tube insertion among preschool-aged children in the United States. Am I Public Health 2000;90(2):245-250. https://doi.org/10.2105/AJPH.90.2.24

24. Carthey J. Breaking the rules: Understanding non-compliance with policies and guidelines. BM 2011;343:1-5. https://doi.org/10.1136/bmj.d5283

25. Black N, Hutchings A. Reduction in the use of surgery for glue ear: Did national guidelines have an impact? Qual Saf Health Care 2002;11(2):121-124. https://doi.org/10.1136/qhc.11.2.121

26. Célind J, Södermark L, Hjalmarson O. Adherence to treatment guidelines for acute otitis media in children: The necessity of an effective strategy of guideline implementation. Int J Pediat Otorhinolaryngol 2014;78(7):1128-1132. https://doi.org/10.1016/.j.jporl.2014.04.029

27. Djurhuus $\mathrm{BD}$, Skytthe $\mathrm{A}$, Christensen $\mathrm{K}$, Faber $\mathrm{CE}$. Increasing rate of middle ear ventilation tube insertion in children in Denmark. Int J Pediatr Otorhinolaryngol 2014;78(9):1541-1544. https://doi. org/10.1016/j.ijporl.2014.06.034

28. Desai S, Kellner J, Drummond D. Population-based, age-specific myringotomy with tympanostomy tube insertion rates in Calgary, Canada. Pediatr Infect Dis J 2002;21(4):348-350

29. Owings M, Kozak L. Ambulatory and inpatient procedures in the United States, 1996. Vital Health Stat 1998:13(139):1-119.

30. Bisset AF, Russell D. Grommets, tonsillectomies, and deprivation in Scotland. BMJ 1994;308:1129. https://doi.org/10.1136/bmj.308.6937.1129

31. Mason J, Freemantle N, Browning G, et al. Impact of Effective Health Care bulletin on treatmen of persistent glue ear in children: Time series analysis. BMJ 2001;323:1096. https://doi.org/10.1136/ bmj. 323.7321 .1096

32. Haapkylä J, Karevold G, Kvaerner KJ, Pitkäranta A. Trends in otitis media surgery: A decrease in adenoidectomy. Int J Pediatr Otorhinolaryngol 2008;72(8):1207-1213. https://doi.org/10.1016/j. ijporl.2008.04.012

Accepted 18 October 2018. 